\title{
Synthesis of biolubricants with high viscosity and high oxidation stability
}

Oléagineux, Corps Gras, Lipides. Volume 10, Numéro 2, 150-4, Mars 2003, FONDAMENTAL

Résumé : Dans ce travail on va discuter la méthode de préparation et les principales propriétés d'un groupe d'esters complexes qui ont été synthétisés à partir d'acides gras à poids moléculaire, du triméthylolpropane et d'acides dicarboxyliques. En utilisant la procédure mise au point, il est possible de préparer, d'une façon simple et rapide des produits ayant une haute viscosité et de très bonnes propriétés à froid et à chaud. La stabilité oxydative est aussi remarquable, grâce à l'absence de doubles liaisons dans la molécule. On peut envisager de nombreuses applications pour cette famille de produits partiellement préparés à partir de sources renouvelables.

Summary : The synthetic procedure as well as the main properties of obtained products of a group of complex esters are reported here. Complex esters were prepared using low molecular weight saturated fatty acids, trimethylolpropane and a dicarboxylic acid as a feedstock. By means of this procedure it is possible to obtain products having high viscosity and very good lubricating, thermal and cold properties. Thanks to the absence of unsaturations into the ester also the oxidation property is good, opening several application perspective for these products which are partly prepared from renewable source.

Mots-clés : biolubrifiants, ester complexe, acide dicarboxylique, stabilité à l'oxidation, trimethylolpropane ester, index de viscosité.

Keywords : biolubricant, complex ester, dicarboxylic acid, oxidation stability, trimetylopropane ester, viscosity index.

\section{ARTICLE}

Auteur(s) : Paolo BONDIOLI

Laura DELLA BELLA

Andrea MANGLAVITI

Stazione Sperimentale Oli e Grassi, Via Giuseppe Colombo, 79, 20133 Milano, MI, Italy

Reçu le 18/9/02

Accepté le 12/12/02

In these last years the use of lubricants made or derived from vegetable oils is in great development, thanks to the increasing environmental concern and to the major attention paid to renewable resources. A huge amount of research projects has been supported by the European Community, in order to promote the research activity as well as the dissemination of knowledge in this field. Among these projects CTVOnet (Chemical Tecnical valorisation of Vegetable Oils) concerted action, ended in 2000 , has been one of the most satisfactory activities in collecting and disseminating information 
within Europe. Among the six sectors of interest, the lubricant and hydraulic fluids group collected a lot of information of this issue. All information were saved and are now available by visiting the CTVOnet website www.fnr.de/ctvo. In these months another very interesting project is in progress: LLINCWA (Lubrication in Inland and Coastal Water Activities): this project consists of a group of demonstrative activities, generally carried out in inland or coastal waters where the use of biolubricants as substitute of mineral oils is carefully studied and evaluated. Also in this case to know more about project a website www.llincwa.org is available.

According to the LLINCWA brochure the term "biolubricants" or "biolubs" includes lubricating oils, lubricating greases, 2-stroke engine oils, hydraulic fluids and chain oils that are non toxic to both humans and aquatic life and can biodegrade in relatively short time. In the same brochure the main drivers for the use of biolubricants are listed:

- high biodegradability;

- low toxicity for humans and aquatic organisms;

- good lubrication properties;

- high viscosity index;

- high flash point;

- good adhesion to metal surfaces.

As usual the dark side of the moon for biolubricants consists of a series of problems generally related with the chemical structure of ester lubricants, generally prepared with mono-unsaturated fatty acids and, in detail:

- low oxidation and thermal stability;

- low temperature behaviour;

- hydrolytic behaviour;

- compatibility with filters and system components.

During the past years the research group active in technology department did several works in synthesising and evaluating vegetable oils or esters prepared from fatty acids [1-5]. With our activity we found that some problems could be partly or totally solved by improving the quality of products. In example hydrolitic stability can be greatly ameliorated by minimizing the concentration of partial esters in polyolesters such as trimethylolpropane oleate (TMPO). The lower the mono- and diester concentration in final product, the lower the water solubility into the system, that is one of the key points in hydrolysis promotion. Also, the residual acidity content is important because free fatty acids, being weak organic acids, act as a catalyst during hydrolysis reaction. The reduction of acid value in finished products greatly improves its hydrolytic stability. Obviously the problem of esters stability in presence of alkaline water still remains and cannot be solved because it is strictly related to the chemical nature of esters. About the resistance towards oxidative damage, the addition of antioxidants, the care in selecting feedstocks, some modifications in equipments, with particular care to the metallic composition, the working temperature and the possibility of air and light contact are 
the weapons generally used to try to buffer this effect. The oxidative degradation of biolubricants is probably the main reason of equipment failure, because of sludge formation (responsible for filters and pipe occlusion) and of acidity formation (responsible for corrosion). In the wide family of ester lubricants there is a class of compounds where the problem of oxidation stability is relatively solved: esters based on saturated low M.W. fatty acids such as octanoic (caprilic $-\mathrm{C}_{8: 0}$ ) and decanoic acid (capric- $\mathrm{C}_{10: 0}$ ). As an example the triester of $\mathrm{C} 8 / \mathrm{C} 10$ acids with TMP is a well known lubricant for jet applications and is very stable towards oxidation as well as cold temperatures (pour point $<-50{ }^{\circ} \mathrm{C}$ ). Unfortunately low MW means also low viscosity, in fact this ester has 17 and $4 \mathrm{~mm}^{2} / \mathrm{sec}$ kinematic viscosity as measured at 40 and $100{ }^{\circ} \mathrm{C}$ respectively. On the other hand the use of higher saturated fatty acids is unfeasible because of the high melting point of esters. Triesters of palmitic or stearic acid have melting points $>50^{\circ} \mathrm{C}$ and are practically stones at ambient temperature. A complete collection of available physical data for different esters is reported in a recent monography [6].

Starting from all these considerations we set up our research work, where the main objective was the synthesis and characterisation of complex esters derived from the condensation of TMP partial esters prepared from C8/C10 fatty acids with dicarboxilic acids such as adipic (C6), azelaic (C9) and sebacic (C10).

The oxidation resistance of these esters was easy to predict, thanks to the absence of double bonds into the molecule, while other properties, such as viscosity, thermal and cold stability properties needed to be experimentally evaluated.

The base molecule for our project is shown in figure 1. With this idea in mind we set up a series of unit operations allowing the preparation and the final refining of complex ester in amount necessary for evaluation tests. We tried to use techniques that could be easily scaled-up for pilot or industrial production. At the same time we evaluated as a feedstock both free fatty acids and corresponding methylesters. The latter might represent a low cost alternative because they are a side-product of lauryl alcohol production from coconut or palm kernel oils.

\section{Material and methods}

\section{Materials}

Caprilic acid (Carlo Erba, Milano, Italy), trimethylolpropane (Fluka/Sigma-Aldrich, Milano, Italy), adipic acid (Merck, Darmstadt, Germany), azelaic acid (Merck, Darmstadt, Germany) and sebacic acid (Merck, Darmstadt, Germany) were for synthesis grade reagents. SnO catalyst was used as TEGOKAT 188 (Th. Goldschmidt AG, Essen, Germany).

\section{Working methods}

Preparation of intermediate ester TMP/caprilic acid: $134 \mathrm{~g}$ of TMP (1 mole) and $259.2 \mathrm{~g}$ (1.8 moles) of caprilic acid were weighed in a 1 I flask equipped with meccanic stirrer, condenser, nitrogen gas dispenser, vacuum connection and heating unit. Temperature was increased up to TMP melting. The catalyst was added $(0.8 \mathrm{~g})$ under strong stirring, the temperature was increased again until $150{ }^{\circ} \mathrm{C}$. The reaction started by production water as a product that can be collected and measured to evaluate the esterification yield. Every hour a sample of reaction mixture was taken and analysed for acid value. Once the targeted acid value reached the reaction was stopped by cooling and the product evaluated in detail. In case of the use of Me caprilate/Me caprate mixture as a feedstock the 
reaction rate was simply evaluated by means of the amount of methanol distilled and finally controlled by capillary GC as described below. When using methylesters as a starting material for intermediate synthesis, the reaction temperature must be increased.

Preparation of final complex ester: the reaction product coming from the synthesis of partial caprilic or caprilic/capric ester was heated up to $60{ }^{\circ} \mathrm{C}$ under stirring in the same apparatus used for first reaction and added of the necessary amount of dicarboxilic acid. The temperature was increased until $150-180^{\circ} \mathrm{C}$ depending on the quality of used dicarboxilic acid. In this case also, the reaction was monitored by means of distilled water and AV determination.

Ester refining after synthesis: several possibilities for product purification after the end of reaction are available from the technical literature of catalyst supplier. $\mathrm{SnO}$ is a heterogeneous catalyst that can be partly recovered at the end of reaction by simple filtration. On the other hand a fraction of added catalyst becomes soluble because of the formation of Sn soaps of fatty acids leading to the most active form of Sn catalyst. Three different techniques leading to a different Sn residual concentration are suggested:

- treatment with $1 \% \mathrm{~m} / \mathrm{m}$ distilled water, under stirring for $30 \mathrm{~min}$ at $80^{\circ} \mathrm{C}$, after treatment filtration through a filter aid. Indicative $S n$ residual $<50 \mathrm{mg} / \mathrm{kg}$;

- treatment with $1 \%$ water suspension of $25 \% \mathrm{~m} / \mathrm{m} \mathrm{CaO}$, under stirring for $30 \mathrm{~min}$ at $80^{\circ} \mathrm{C}$, after treatment filtration through a filter aid. Indicative $\mathrm{Sn}$ residual $<10 \mathrm{mg} / \mathrm{kg}$;

- treatment with $1 \% \mathrm{~m} / \mathrm{m} 10 \%$ solution $\mathrm{H} 2 \mathrm{O} 2$, under stirring for 30 min at $80^{\circ} \mathrm{C}$, after treatment filtration through a filter aid. Indicative $\mathrm{Sn}$ residual $<1 \mathrm{mg} / \mathrm{kg}$.

In table 1 results obtained by treatment with $\mathrm{CaO}$ and $\mathrm{H} 2 \mathrm{O} 2$ of the final product of this work are reported. The determination of metals was carried out by means of ICP-AES.

Table 1. Residual metallic contamination in finished lubricant after two different refining treatments (see text for experimental details). Results expressed as $\mathrm{mg} / \mathrm{kg}$.

\section{Ester purified with $\mathrm{CaO} \quad$ Ester purified with \\ technique H2O2 technique}

$\mathrm{Mg}$

$\mathrm{Zn}$

P

$\mathrm{Fe}$

$\mathrm{Ca}$

Al

$\mathrm{Sn}$
14

39

38

4

137

1

17
$<1$

3

$<3$

1

$<1$

1

4 


\section{Analytical methods}

Acid value was determined using UNI EN ISO 660:1999, hydroxyle value was determined according to NGD C34:1976, viscosity at 40 and $100{ }^{\circ} \mathrm{C}$ as well as viscosity index were determined according to ASTM D445:2001 and ASTM D2270:1998 respectively; pour point was determined according to ISO 3016:1995, Noack test was carried out according to CEC L 40A:1993 (2000), flash and fire Points were determined according to ASTM D93: 2000 and ASTM D92:2001.

The evaluation of the composition of result of the first intermediate reaction was made using an adapted UNI 22053:1997 method. The method was originally set-up for biodiesel evaluation, where it was necessary to detect all the possible forms of partial esters. A GC instrument mod. TRACE 2000 (Thermoquest, Rodano, Italy) equipped by cold on-column injector, a capillary column of type DB5HT (J\&W Scientific Folsom, CA, USA) ID $0.32 \mathrm{~mm}$, film thickness $0.1 \mu \mathrm{m}$, length $10 \mathrm{~m}$ and a FID detector thermostated at $350^{\circ} \mathrm{C}$ was used. The oven temperature program was low isothermal at $80^{\circ} \mathrm{C}$ for $1 \mathrm{~min}$, then at $300^{\circ} \mathrm{C}$ (high isoterm for $10 \mathrm{~min}$ ) at heating rate of $5{ }^{\circ} \mathrm{C} / \mathrm{min}$. The sample (approximately $10 \mathrm{mg}$ ) was taken as it was from the reaction mixture, treated with $200 \mu \mathrm{l}$ of bistrimthylsilyl trifluoro acetamide (BSTFA, Aldrich Chemical Co., Milwaekee, IL, USA) and $200 \mu \mathrm{l}$ of pyridine silyl grade (Pierce, Rockford, IL, USA). After $20 \mathrm{~min}$ of reaction at ambient temperature the sample was treated under a nitrogen flow to remove volatile reagents, diluted up to $8 \mathrm{ml}$ with isooctane and analysed in GC. The resulting path allows to evaluate all possible chemical species from free TMP up to TMP triester. The quantitative evaluation was done by measuring the percent area of each peak.

Regarding the oxidation stability evaluation a test method originally proposed by Naegely [7] and successfully used in our previous papers was used. It consists of maintaining $40 \mathrm{~g}$ of sample in a test tube thermostated at $120^{\circ} \mathrm{C}$ under an air or oxygen flow and measuring each day the $100{ }^{\circ} \mathrm{C}$ kinematic viscosity of sample. The higher the oxidation extent, the higher the viscosity increase. In said conditions samples of neat vegetable oil sometimes became completely solid, while more stable products such as mineral oils do not show any significant change in viscosity.

\section{Results and discussion}

Our work was oriented towards a possible scale-up of the production technology: we therefore decided to avoid the use of organic solvents or protection groups during TMP partial esterification with caprilic/capric acid or methylester. The use of protecting groups is a very efficient technique to carry out partial and selective esterifications of polyalcohols. Among the wide variety of possible examples we can remember the possibility of protecting $-\mathrm{OH}$ moieties in position 2 and 3 of glycerol by means of the preparation of isoproprylidenacetone by reacting glycerol with acetone. The successive esterification with fatty acids allows for the selective preparation of 1-acyl isopropylidenacetone that, after weak hydrolisis of chetal group, leads to the preparation of 1monoglyceride [8].

Once decided to avoid the use of protective groups, we must accept that our final reaction mixture will contain several different products, representing all possible combinations also in consideration of the stoichometric ratio existing between reactants. 
In table 2 the kinetics of direct partial esterification of TMP with caprilic acid is reported. In order to reach a yield $>99 \%$ it is necessary to continuously remove water from the reaction mixture. The reaction is nearly complete in three hours. The successive GC analysis gives a path such as reported in figure 2.

Table 2. Kinetic of intermediate ester preparation, TMP: caprylic acid 1:2 in moles, temperature $150{ }^{\circ} \mathrm{C}$, catalyst $0.8 \mathrm{~g}$. Results expressed as residual $\mathrm{AV}(\mathrm{mg} / \mathrm{KOH} / \mathrm{g})$

\begin{tabular}{||l|l|}
\hline Reaction time, hours & Acid Value \\
\hline 0 & 265.9 \\
\hline 1 & 72.6 \\
\hline 2 & 10.2 \\
\hline 3 & 0.4 \\
\hline 4 & 0.3 \\
\hline 5 & 0.3 \\
\hline
\end{tabular}

The indicative composition of the mixture is:

\begin{tabular}{ll} 
Free TMP & $1.93 \%$ \\
TMP monoester & $17.99 \%$ \\
TMP diester & $45.20 \%$ \\
\hline TMP triester & $34.88 \%$
\end{tabular}

More complex mixtures can be obtained using a feedstock constituted of $\mathrm{C} 8 / \mathrm{C} 10$ fatty acids or methylesters instead of pure $\mathrm{C} 8$ acid or ester. Figure 3 shows the corresponding GC path.

The composition of mixture becomes more and more complex at the end of the second reaction: by reacting a four component mixture, we must consider that two molecules of diester by reaction with a molecule of dicarboxylic acid can give the molecule indicated in figure 1 as the base of our research (dimer of TMP dicaprilate). But the presence of a TMP monoester with two free $-\mathrm{OH}$ moieties can act as a promoter for oligomerisation leading to the formation of trimers, tetramers, etc. On the contrary the tricaprilate ester of TMP can be regarded as an inert product because all $-\mathrm{OH}$ moieties are blocked by an ester group. The concentration of these products is only a function of stoichometric ratio between the different reactants. A HPLC-MS approach of the final mixture allowed the identification of TMP mono-, di- and tricaprilate, along with TMP caprilate dimer, trimer and tetramer in decreasing concentration. During the same control also two intermediates showing free $-\mathrm{OH}$ groups were detected (TMP dimer tricaprilate and TMP trimer tetracaprilate). 
In table 3 the kinetics of the second reaction carried out with different dicarboxilic acids is shown. Practically no differences were detected in reaction rate for adipic and azelaic acid, while sebacic acid shows a slower one. Nevertheless in every case it was possible to reach an acceptable conversion rate for each complex ester.

Table 3. Kinetic of final product preparation by reacting dicarboxilic acid in stoichometrical amount with intermediate ester. Data related to final product were obtained after catalyst removal using $\mathrm{H}_{2} \mathrm{O}_{2}$. Results expressed in $\mathrm{mg} \mathrm{KOH} / \mathrm{g}$ for both $\mathrm{AV}$ and $\mathrm{NOH}$

\begin{tabular}{||l|l|l|l|l|}
\hline \hline Reaction time, hours & $\begin{array}{l}\text { Ester with } \\
\text { adipic acid }\end{array}$ & $\begin{array}{l}\text { Ester with azelaic } \\
\text { acid }\end{array}$ & $\begin{array}{l}\text { Ester with } \\
\text { sebacic acid }\end{array}$ \\
\hline 0 & 117.5 & 97.9 & 94.7 \\
\hline 2 & 40.4 & 13.1 & 16.7 \\
\hline 4 & 1.5 & 5.6 & 2.1 \\
\hline 6 & 0.8 & 0.8 & 1.8 \\
\hline 8 & 0.7 & 0.7 & 1.8 \\
\hline Final product & & & \\
\hline AV & 0.6 & 0.7 & \\
\hline NOH & 13.1 & 15.7 & \\
\hline
\end{tabular}

As a second part of our work we decided to carry out the characterisation of obtained products with the final scope of identifying applications for them. In table 4the main properties of the three complex esters are reported. The kinematic viscosity increases when MW increases, but the viscosity index shows opposite behaviour. For the continuation of our work we decided to draw out attention only towards the ester prepared with adipic acid, because adipic acid is the cheapest dicarboxylic acid and probably is the only one available in bulk quantities. Very interesting and promising is the pour point, trespassing the $-50^{\circ} \mathrm{C}$ value probably thanks to the high ramification degree of molecules. For flash and pour point the obtained values, very good, are only the confirmation of antifire properties of ester lubricants. 
Table 4. Main physical properties of different esters

\begin{tabular}{|l|l|l|l|}
\hline & $\begin{array}{l}\text { Ester with } \\
\text { adipic acid }\end{array}$ & $\begin{array}{l}\text { Ester with } \\
\text { azelaic acid }\end{array}$ & $\begin{array}{l}\text { Ester with } \\
\text { sebacic acid }\end{array}$ \\
\hline $\begin{array}{l}40^{\circ} \mathrm{C} \mathrm{Kinematic} \\
\text { Viscosity, } \mathrm{mm}^{2} / \mathrm{sec}\end{array}$ & 86.00 & 82.90 & 93.43 \\
\hline $\begin{array}{l}100{ }^{\circ} \mathrm{C} \mathrm{Kinematic} \\
\text { Viscosity, } \mathrm{mm}^{2} / \mathrm{sec}\end{array}$ & 14.47 & 13.00 & 13.08 \\
\hline Viscosity Index & 176 & 157 & 138 \\
\hline Pour Point, ${ }^{\circ} \mathrm{C}$ & $<-50$ & ND & ND \\
\hline Flash Point, ${ }^{\circ} \mathrm{C}$ & 264 & ND & ND \\
\hline Fire Point, ${ }^{\circ} \mathrm{C}$ & 298 & ND & ND \\
\hline
\end{tabular}

Also the thermal stability as measured according to Noack test is very good for the proposed product: our results indicate that the Noack losses are of $2.3 \% \mathrm{~m} / \mathrm{m}$ for our products versusa typical value of $8-15 \% \mathrm{~m} / \mathrm{m}$ generally accepted for mineral oils for automotive application. The obtained value is not surprising for ester products and only depends on MW as demonstrated in our previous work [5], where the Noack losses for different esters based on Crambe abyssinicafatty acids were determined. The results obtained in this case are very important because on one side they show that the prepared ester is thermally stable and on the other side it shows a low volatility under test conditions $\left(250^{\circ} \mathrm{C}\right)$. Low volatility also means reduced oil transfer in environment during use in hot applications such as engine or quenching oils.

The last test we did is the evaluation of oxidation stability. In table 5 the results obtained during the evaluation of two ester samples, with different metal contamination are listed. During the same test we also evaluated a SN 150 mineral base oil as a reference. The mineral oil sample did not show any significant change during the whole test. Also our product behaves very well under test conditions, showing only light changes in $100{ }^{\circ} \mathrm{C}$ kinematic viscosity. The stability differences existing between the two samples are more obious in volatile acidity measurements than in viscosity. Looking at the second part of the table we can see the dramatic difference in volatile acidity release in two samples. Sample A, where metal content was only partly removed shows a strong volatile acidity release. Taking into account the particular nature of the sample and the presence in the molecule of C8 fatty acid that can be regarded as volatile under test conditions, we can assume that the result in volatile acidity can be the result of both oxidation and hydrolysis of the tested product. For a better evaluation of obtained results we found that soybean, sunflower oil became solid after 72 hours of 
treatment [2, 7], rapeseed (high erucic) and sunflower (high oleic) increase 26 and 10 times their $100{ }^{\circ} \mathrm{C}$ kinematic viscosity in 72 hours respectively $[2,7]$ and finally TMP ester prepared from Crambe Abyssinica fatty acids increases 11 times in 72 hours [5].

Table 5. Oxidation stability test carried out on two samples of ester with adipic acid purified by means of CaO treatment (Sample A) and H2O2 treatment (Sample B). Kinematic Viscosity expressed as $\mathrm{mm}^{2} / \mathrm{sec}$, Volatile acidity as $\mathrm{mg} \mathrm{KOH} /$ day

\begin{tabular}{|c|c|c|c|c|c|}
\hline $100^{\circ} \mathrm{C}$ & Time 0 & Time $24 \mathrm{~h}$ & Time $48 \mathrm{~h}$ & Time $72 \mathrm{~h}$ & Time $96 \mathrm{~h}$ \\
\hline \multicolumn{6}{|c|}{ Kinematic Viscosity } \\
\hline Sample A & 15.05 & 15.52 & 15.91 & 17.37 & 18.71 \\
\hline Sample B & 13.03 & 13.43 & 14.03 & 14.58 & 14.71 \\
\hline \multicolumn{6}{|c|}{ Volatile Acidity } \\
\hline Sample A & & 1.40 & 36.46 & 101.82 & 141.65 \\
\hline Sample B & & 1.26 & 1.12 & 1.40 & 1.40 \\
\hline
\end{tabular}

\section{Conclusion}

With our experimental work we have demonstrated the feasibility of the synthesis, refining and potential application of some esters contemporarily showing high viscosity, low volatility and very good oxidation stability. The proposed ester is only partly prepared using renewable feedstocks (practically low MW fatty acids or methylesters), while the polyalcohol is of petrochemical origin as well as adipic acid. The use of azelaic or sebacic acid, prepared from oleic acid and ricinoleic acid respectively might increase the renewable fraction of this oil. Furthermore, the possibility to obtain adipic acid from renewable source by ozonolysis of petroselinic acid (cis-7 octadecenoic acid) from Coriander sativum oil was recently announced [9]. In every case a quick check at safety data sheets of each feedstock will confirm the complete safety of each used ingredient. Carrying on this work mean scaling up of the production technology and, more important, identifying possibilities of use in different sectors of this product, where its environmentally-friendly nature and interesting lubrication properties might be maximised.

\section{Acknowledgments:}

Many thanks to Pierangela Rovellini (HPLC department) and Maura Sala (Mineral oil department) of our institute, for the irkind contribution they provided in HPLC-MS and lubricants evaluation respectively. 


\section{REFERENCES}

1. Bondioli P, Folegatti L, Lazzeri L, Palmieri S. Native Crambe abyssinica oil and its derivatives as renewable lubricants: an approach to improve its quality by a chemical or biotechnological process. Industrial Crops and Products $1998 ; 7: 231$

2. Bondioli P. Basics of oleochemistry for lubricant production. Paper presented at $1^{\text {st }}$ CTVOnet Workshop on Lubricants and Hydraulic Fluids. Eibar, Spain $17^{\text {th }}$ February 1999.

3. Bondioli P. and Sabarino G.P. The identification and evaluation of natural and synthetic esters in mimeral oils. Tribotest Journal, 6: 125 (Reprint of Italian paper published in Riv It Sostanze Grasse $1999 ; 74: 423$ (1997))

4. Bondioli P, Berardi S. About the possibility to detect vegetable oils in trymethylolpropane oleate samples (It.). Riv It Sostanze Grasse $1999 ; 76: 225$.

5. Bondioli P, Inzaghi L, Postorino G, Quartuccio P. Crambe abyssinica oil and its derivatives as renewable lubricants: synthesis and characterisation of different esters based on Crambe fatty acids. J Synth Lubr 15: 271 (Reprint of original paper published in Riv It Sostanze Grasse 1999 ; 74 : 137 (1997))

6. Bondioli P. Lubricants and Hydraulic Fluids. In « Oleochemical Manufacture and Application » by Gunstone F.D. and Hamilton R.J. (Editors), Sheffield Academic Press, Sheffield, UK 2001.

7. Naegely PC. Environmentally acceptable lubricants. In "Seed oils for the future", by Mac Kenzie S.L. and Taylor D.C. (Editors), AOCS Press, Champaign, IL, USA, 1993.

8. Hartman L. Preparation of 1-monoglyceride by a modified glycerol-isopropylidene method. Chemistry and Industry $1960 ; 711$.

9. ACTIN (Alternative Crops Technology International Network) Newsletters no. 11, February 1999, Leatherhead, UK. 


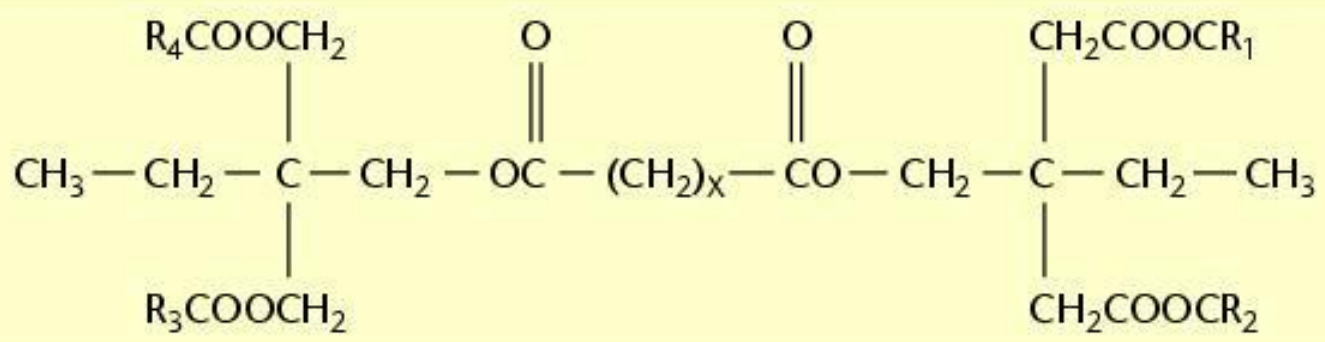

Figure 1. Chemical structure of complex ester.

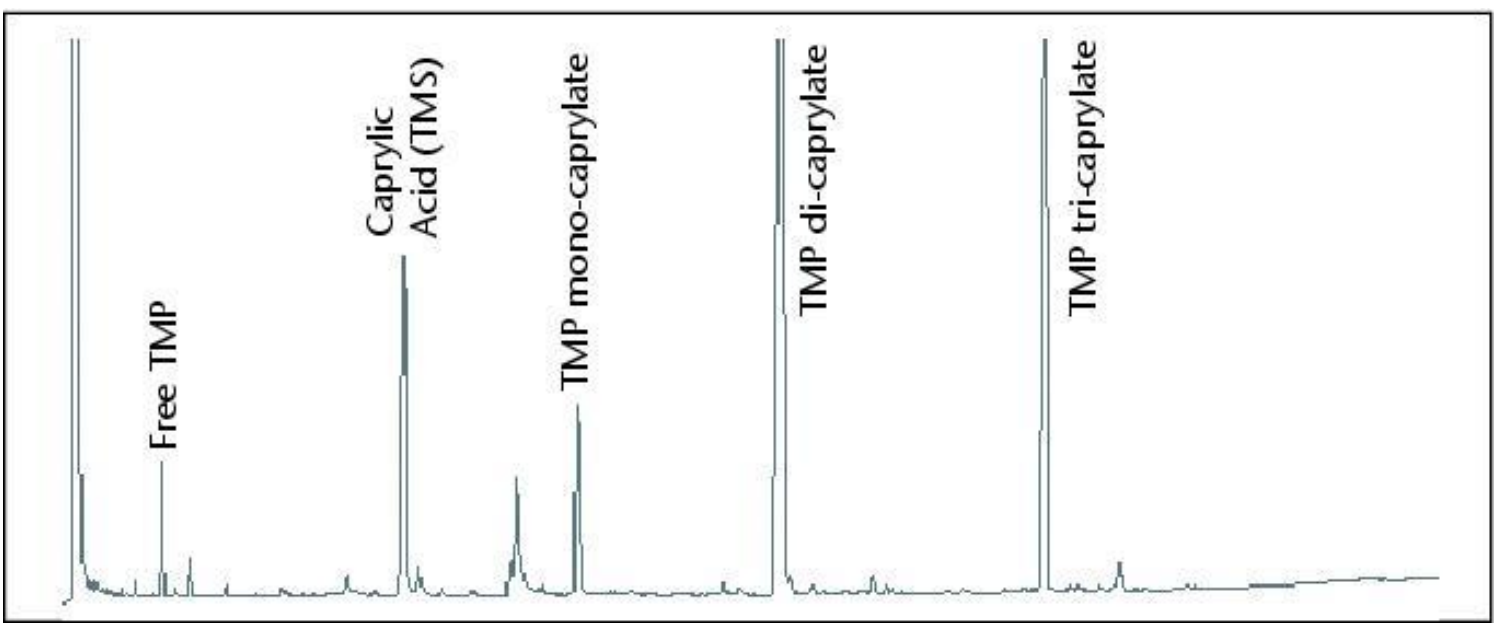

Figure 2. GC analysis of intermediate ester. Reaction with caprylic acid.

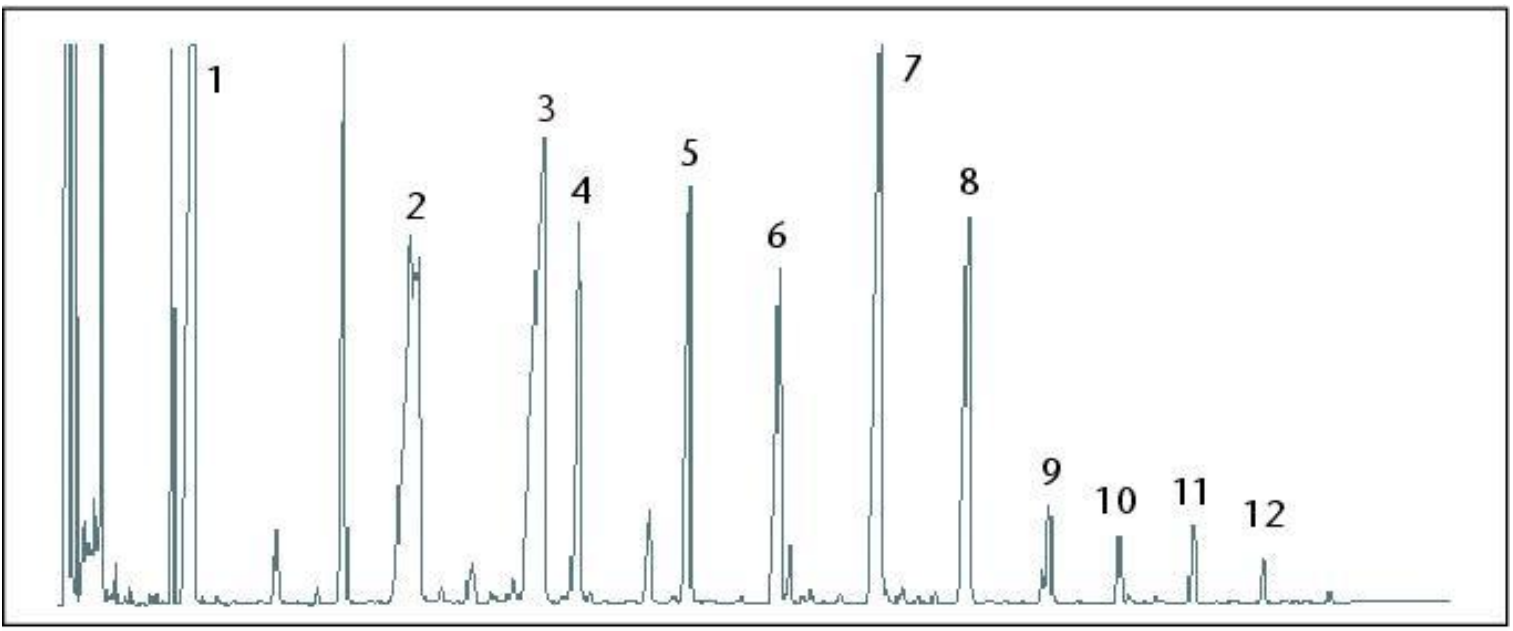

Figure 3. GC analysis of intermediate ester. Reaction with caprylic (C8) and capric (C10) methylesters (Me). Peak identification: 1-Free TMP; 2-C8 Me; 3-C10 Me; 4-C8 TMP monoester; 5-C10 TMP monoester; $6-C 8+C 8$ diester; $7-C 8+C 10$ diester; $8-C 10+C 10$ diester; $9-C 8+C 8+C 8$ triester; $10-C 8+C 8+C 10$ triester; $11-C 8+C 10+C 10$ triester; $12-C 10+C 10+C 10$ triester. 